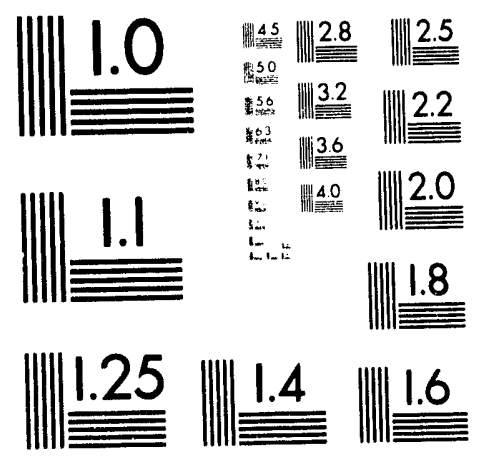



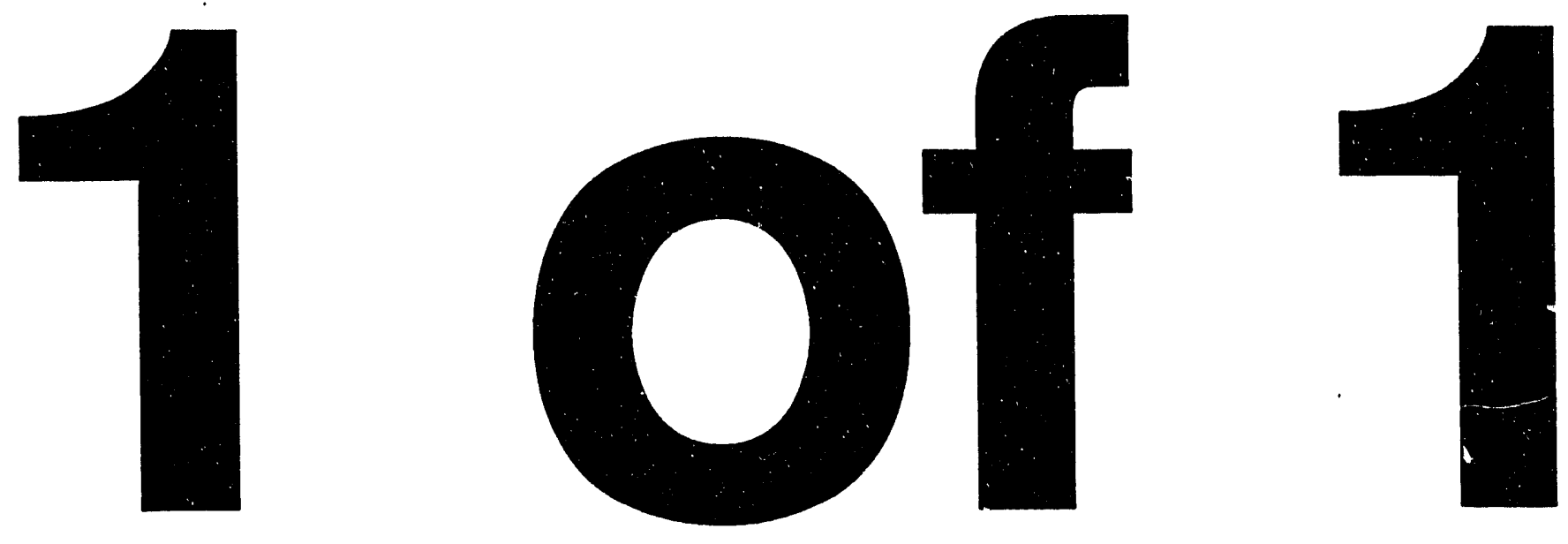
TITLE: CRYSTAL ORIENTATION DEPENDENCE OF ELASTIC PRECURSOR STRENGTH IN PENTAERYTHRITOL TETRANITRATE

AUthoR(S): Jerry J. Dick, M.C. Whitehead, A.R. Martinez, LANL, M-7

SUBMITTED to: Joint AIRAPT/APS Conference - American Physical Society June 28 - July 2, 1993, Colorado Springs, CO

\section{DISCLAIMER}

This report was prepared as an account of work sponsored by an agency of the United States Government. Neither the United States Government nor any agency thereof, nor any of their employees, makes any warranty, express or implied, or assumes any legal liability or responsibility for the accuracy, completeness, or usefulness of any information, apparatus, product, or process disclosed, or represents that its use would not infringe privately owned rights. Reference herein to any specific commercial product, process, or service by trade name, trademark, manufacturer, or otherwise does not necessarily constitute or imply its endorsement, recommendation, or favoring by the United States Government or any agency thereof. The views and opinions of authors expressed herein do not necessarily state or reflect those of the United States Government or any agency thereof.

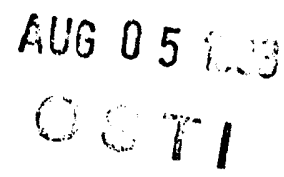




\title{
CRYSTAL ORIENTATION DEPENDENCE OF ELASTIC PRECURSOR STRENGTH IN PENTAERYTHRITOL TETRANITRATE
}

\author{
J. J. Dick, M. C. Whitehead, and A. R. Martinez \\ Group M-7 \\ Los Alamos National Laboratory \\ MS P952 \\ Los Alamos, New Mexico 87545
}

Elastic preci rsor shock strengths were measured using VISAR instrumentation on pentaerythritol tetranitrate crystals 2.9 to $6.4 \mathrm{~mm}$ thick. Input shock strength was $1.2 \mathrm{GPa}$. A factor of 3 difference in elastic shock strength and a factor of 2 difference in critical resolved shear stress were observed depending on the crystal orientation. The order of increasing elastic shock strength was [100], [101], [110], and [001]. This is the same order as that obtained in our analysis for increasing steric hindrance to shear, indicating that the relative strength of different orientations of this molecular crystal under shock conditions is governed by steric hindrance to shear.

\section{INTRODUCTION}

In previous work we have shown that the shock initiation sensitivity of pentaerythritol tetranitrate (PETN) single crystals depends strongly on crystal orientation relative to the plane shock wave.1,2 The effect has been explained in terms of a model at the molecular level for the steric hindrance to the shear induced by the uniaxial strain generated by a plane shock wave. ${ }^{2,3}$ In a crystal the shear occurs on a crystallographic slip plane and direction as illustrated in Fig. 1. It takes place on a slip plane near $45^{\circ}$ to the shock propagation direction, particularly on the slip system that has the maximum resolved shear stress (MRSS) generated by the longitudinal stress of the compressive shock.

The critical resolved shear stress is the shear stress that must be applied on the MRSS slip system to cause the onset of plastic or irreversible, inelastic flow. In a molecular crystal it is likely that this critical resolved shear stress determining the yield point for a given orientation is determined to some extent by the steric hindrance to shear. The sterically hindered shear has a dramatic effect on the shock sensitivity of PETN. Furthermore, the preferred slip system observed in quasistatic deformation of PETN crystals' is not the one with the shortest Burgers vector as is expected from the standpoint of energetics in simple atomic lattices. Rather, it is the one that our calculations show has the least steric hindrance to shear. Based on these observations we conclude that the elastic precursor shock strength st:ould correlate with the amount of steric hindrance. The sterically hindered orientations should have large elastic precursors, and the unhindered orientations should have small precursors. We report on a series of VISAR interferometer experiments undertaken to verify this hypothesis.

\section{VISAR EXPERIMENTS}

A series of impact experiments was performed using a light-gas gun.. An aluminum projectile impacted a plus- $x$-cut quartz crystal $5 \mathrm{~mm}$ thick. The PETN crystal slab (3 to $6 \mathrm{~mm}$ thick) was bonded to the quartz with Sylgard 184 silicone elastomer. A mirrored polymethylmethacrylate (PMMA) window was bonded to the crystal with the elastomer. The motion of the PETN/PMMA interface was monitored with a VISAR laser interferometer. Transit time through the PETN was measured using a PZT pin on the quartz crystal and the VISAR signal. Impact velocities were about $0.3 \mathrm{~mm} / \mu \mathrm{s}$. The longitudinal stress for the plastic wave was estimated to be about 1.2 GPa. Experiments were performed on specimens about 3 and $6 \mathrm{~mm}$ thick for each of the four orientations, $[100],[101],[110]$, and [001], given in order of increasing steric hindrance. Particle velocity histories for the thick 


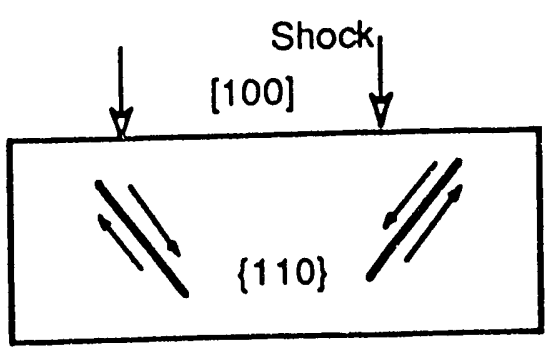

Unhindered shear, insensitive

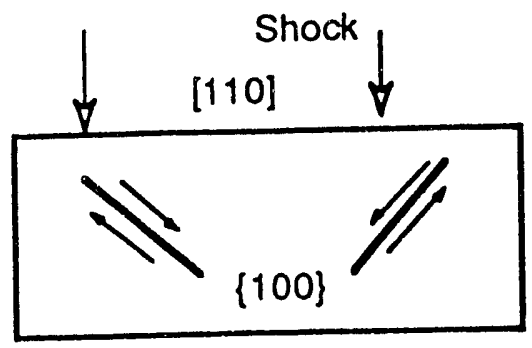

Hindered shear, sensitive

Figure 1. Schema of the relative orientations of shock and shear planes. When the sterically unhindered $\{110\}$ plane is available for shear, the crystal is insensitive and has a small elastic precursor. When the slip system is hindered $(\{100\}<011\rangle$, e.g. $)$ the crystal is sensitive and has a large elastic precursor.

samples of all four orientations are displayed in Fig. 2. The results show that the the elastic precursor strength for a given input strength increases with increasing steric hindance as predicted. The results are consistent with the earlier results of $P$. Halleck and J. Wackerle ${ }^{5}$ and $\mathrm{L}$. Soulard ${ }^{6}$ for the hindered orientations. No significant precursor decay was observed between 3 and $6 \mathrm{~mm}$ for all orientations. Results for the [101] orientation are shown in Fig. 3. Any decay must have occurred in less than $3 \mathrm{~mm}$ of run. Preliminary analysis of the longitudinal stresses has been performed. In order of increasing size, the longitudinal elastic stress in PETN is about $0.37 \mathrm{GPa}$ for a [100] shock, 0.58 $\mathrm{GPa}$ for a [101] shock, 1.0 GPa for a [110] shock, and $1.2 \mathrm{GPa}$ for [001] shock. The corresponding critical resolved shear stresses on the MRSS slip system are $1.1,1.6,2.1$, and $2.2 \mathrm{GPa}$, respectively. These rankings are the same as the steric hindrance from least to most hindrance (see Table 1) providing convincing supporting evidence for the steric

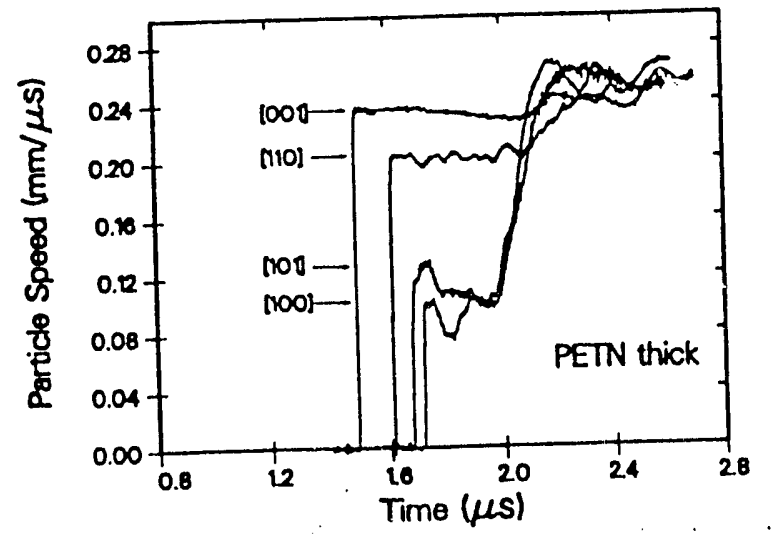

Figure 2. Elastic-plastic wave profiles at the PETN/PMMA interface for thick crystals of the four orientations. The strongly hindered orientations [001] and [110] have larger elastic precursor shocks than the weakly hindered orientations [101] and [100].

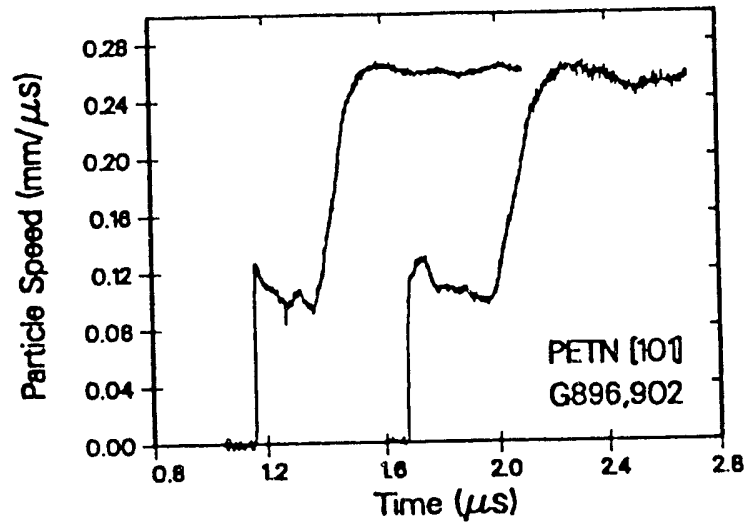

Figure 3. Elastic-plastic wave profiles at the PETN/PMMA interface for the [101] orientation for crystals 4.30 and 6.13 mm thick.

hindrance model.

The steric hindrance analysis given in Table 1 enumerates the number and types of close approaches closer than $1.70 \AA$ for shear across the unit cell by rigid molecules. The closest approaches are clearly unphysical. The equilibrium, molecularmechanics analysis of $\mathrm{J}$. Ritchie ${ }^{3}$ for flexible molecules shows that atomic groups on the molecules can rotate and bend out of each others way so 
Täole 1. Atom-Atom Interactions for PETN.

\begin{tabular}{|c|c|c|c|c|c|c|}
\hline \multirow[b]{2}{*}{$\begin{array}{c}\text { Shock } \\
\text { Direction }\end{array}$} & \multirow[b]{2}{*}{$\begin{array}{l}\text { MRSS }^{\circ} \text { Slip } \\
\text { System }\end{array}$} & \multirow[b]{2}{*}{$\begin{array}{l}\text { Atom } \\
\text { Pair }\end{array}$} & \multicolumn{2}{|c|}{ Body-Centered Molecule } & \multicolumn{2}{|c|}{ Comer Molecule } \\
\hline & & & $\begin{array}{l}\text { Number of } \\
\text { Interactions }\end{array}$ & $\begin{array}{c}\text { Closest } \\
\text { Approach } \\
(\AA)\end{array}$ & $\begin{array}{l}\text { Number of } \\
\text { Interactions }\end{array}$ & $\begin{array}{c}\text { Closest } \\
\text { Approach } \\
\text { (A) } \\
\end{array}$ \\
\hline \multirow[t]{2}{*}[100]{} & $\{110\}<1 I 1>$ & $0-0$ & 3 & 1.05 & 1 & 1.65 \\
\hline & $\{110\}<001>b$ & 0.0 & 2 & 0.78 & 2 & 0.78 \\
\hline \multirow{9}{*}{$\begin{array}{l}{[101]^{c}} \\
{[110]^{c}}\end{array}$} & $\{100\}<001>$ & $0-0$ & 4 & 0.78 & 4 & 0.78 \\
\hline & $\{100\}<011>$ & $0-0$ & 9 & 0.54 & 9 & 0.54 \\
\hline & & N-O & 5 & 1.01 & 5 & 1.01 \\
\hline & & $\mathrm{C}-\mathrm{O}$ & 2 & 0.83 & 2 & 0.83 \\
\hline & & $\mathrm{O}-\mathrm{H}$ & 6 & 0.31 & 6 & 0.31 \\
\hline & & $\mathrm{N}-\mathrm{H}$ & 4 & 0.80 & 4 & 0.80 \\
\hline & & $\mathrm{H}-\mathrm{H}$ & 2 & 0.99 & 2 & 0.99 \\
\hline & & $\mathrm{N}-\mathrm{N}$ & 1 & 1.58 & 1 & 1.58 \\
\hline & & $\mathrm{C}-\mathrm{N}$ & $\frac{1}{30}$ & 1.60 & $\frac{1}{30}$ & 1.60 \\
\hline \multirow[t]{7}{*}[001]{} & $\{101\}<101>$ & $0-0$ & 3 & 0.86 & 12 & 0.86 \\
\hline & & $\mathrm{C}-\mathrm{O}$ & 4 & 0.71 & 6 & 0.71 \\
\hline & & $\mathrm{O}-\mathrm{H}$ & 6 & 0.11 & 10 & 0.11 \\
\hline & & $\mathrm{N}-\mathrm{H}$ & 2 & 1.01 & 2 & 1.00 \\
\hline & & $\mathrm{C}-\mathrm{N}$ & 1 & 1.52 & 1 & 1.52 \\
\hline & & N-O & 1 & 1.38 & 5 & 1.00 \\
\hline & & $\mathrm{N}-\mathrm{N}$ & $\frac{0}{17}$ & & $\frac{2}{38}$ & 1.58 \\
\hline
\end{tabular}

- MRSS $\equiv$ Maximum resolved shear stress.

'Slip system expected from the standpoint of the shortest Burgers vector and widest interplanar separation.

cInteractions are with the body-centered or the comer molecule

but not both, for a given shear.

that the closest atom-atom approaches are greater than $2 \AA$, in general. Nonetheless, the correlation of the simple, geometric analysis using rigid molecules with experimental results for elastic precursor dependence and with the energy barrier to shear computed with molecular mechanics indicates that the geometric analysis captures the extent of physical hindrance to some degree.

In Ref. 2 we presented a table of geometric hindrance for only the interactions of the bodycentered molecule. In Table 1 the complete analysis is given including the interactions for the comer molecule, the other molecule per unit cell. The major change is that now the slip system [001] shocks shows the most interactions even though [110] crystals are most sensitive, indicating the limitations of the geometric analysis in describing the physical and chemical behavior of the crystals under shock conditions. It is interesting to note that the $\{110\}<001>$ slip system which might be expected to be the preferred slip from the standpoint of having lower energy in atomic lattices from the standpoint of having a shorter Burgers vector ${ }^{7}$ has the same number of interactions but closer interactions than the observed $\{110\}<1 \overline{11}>$ slip system, so that the geometric analy'sis as well as the molecular mechanics analysis ${ }^{3}$ is in agreement with experimental observations. This indicates that that steric hindrance controls the preferred slip system even under quasistatic deformation.

The nature of the shear or slip process in PETN under shock conditions is not known with certainty. In quasistatic deformation in indenter tests deformation by generation and growth of dislocation loops is observed. ${ }^{4}$ Since $[100]$ shocks apparently use the same slip system as quasistatic deformation, it is possible that dislocation processes govem the plastic shear flow for this case under shock conditions, especially at low shock strengths. It was observed earlier ${ }^{8}$ that for the strongly hindered [110] and [001] shocks that the resolved shear stress may exceed the estimated strength of the perfect crystal. In that case, supercritical or simultaneous shear may be occurring. 
There are some results that indicate that the elastic precursor strength is strongly dependent on input shock strength for these orientations. 5,9

\section{ACKNOWLEDGMENTS}

Thanks to Jim Ritchie for helpful convr sations and interactions. This work was performed under the auspices of the U. S. Department of Energy and partially supported by the Office of Munitions Memo of Understanding between the Department of Energy and the Department of Defense.

\section{REFERENCES}

1. J. J. Dick, Appl. Phys. Lett. 44, 859 (1984).

2. J. J. Dick, R. N. Mulford, W. J. Spencer, D. R. Pettit, E. 2. J. J. Dick, R. N. Murcia, and D. C. Shaw, J. Appl. Phys. 70, 3572 (1991).

3. J. P. Ritchie, "Computational Analysis of Slip in PETN," presented at the Tenth Symposium (Intemational) on De:onation, Boston, MA, July 12-16, 1993.

4. H. P. Gallagher, P. J. Halfpenny, J. C. Miller, and J. N. Sherwood, Phil. Trans. R. Soc. of Lond. A 339, 293 (1992).

5. P. M. Halleck and Jerry Wackerle, J. Appl. Phys. 47, 976 (1976).

6. L. Soulard, Thesis, Etude du Monocristal de Pentrite Soumis a un Choc Plan, L'Universite de Haute Alsace, 1990 , p. 30.

7. J. P. Hirth and J. Lothe, Theory of Dislocations, Malabar, Florida:Krieger Publishing Company, 1992, ch. 9, p. 271.

8. J. J. Dick, Appl. Phys. Lert. 60, 2494 (1992).

9. J. J. Dick, to be published. 


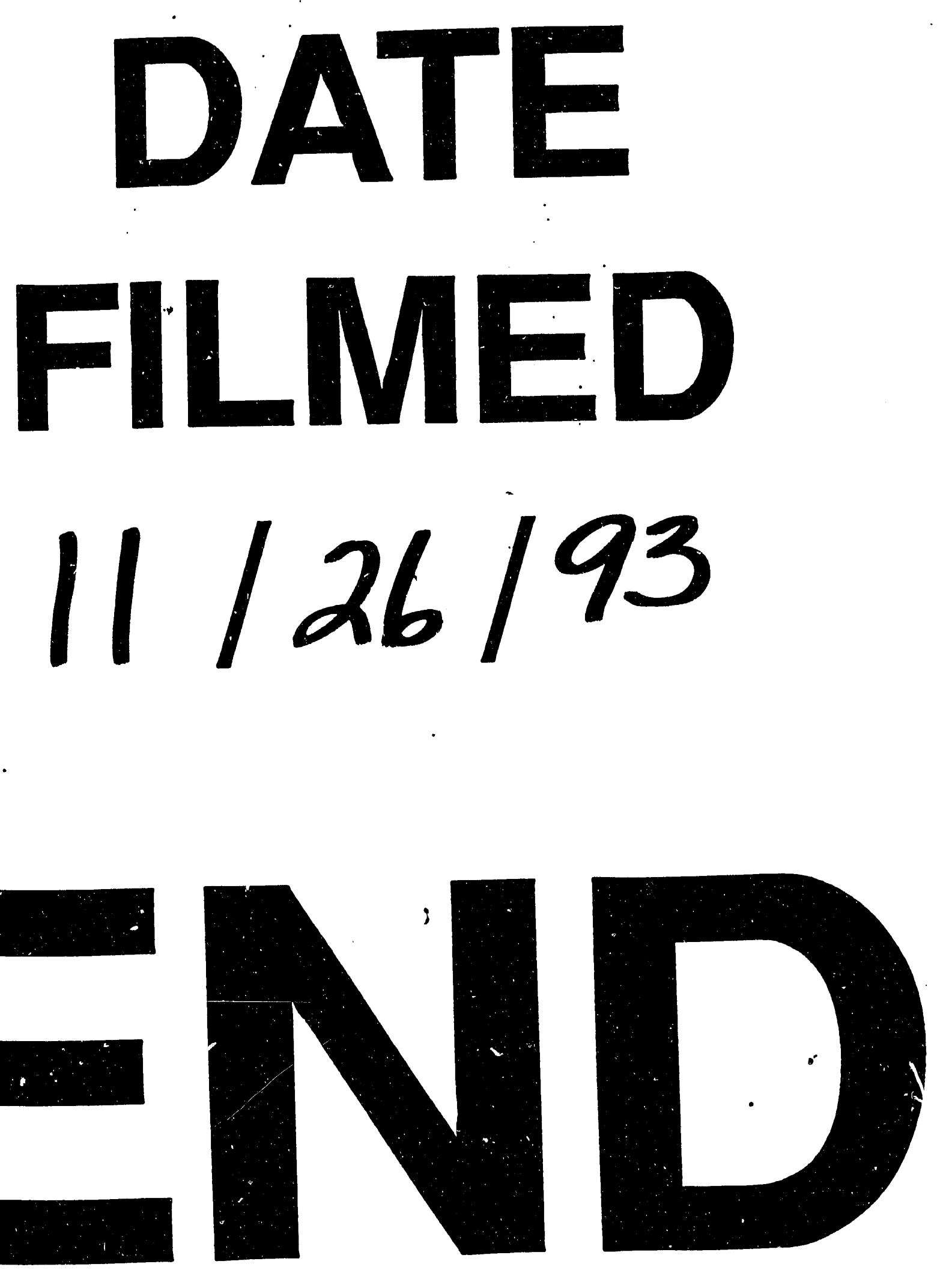




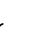

